\title{
Correction: A general solution of the Fekete-Szegö problem
}

Jacek Dziok ${ }^{*}$

\section{"Correspondence:}

jdziok@univ.rzeszow.pl

Institute of Mathematics, University

of Rzeszów, Rzeszów, 35-310, Poland

\section{Correction}

Errata of the paper [1]. Corrections are listed in Table 1.

Table 1 The list of corrections

\begin{tabular}{lll}
\hline Page/Line & Incorrect & Correct \\
\hline $3 / 6$ & $\mathcal{C} \mathcal{W}(\Phi ; p, p)$ & $\mathcal{C W}(\Phi ;(p, p))$ \\
$5 / 2$ & $\frac{\left|p_{1}\right|}{(1+\alpha)\left|\alpha_{2}\right|}$ & $\frac{\left|p_{1}\right|}{|1+\alpha|\left|\alpha_{2}\right|}$ \\
$5 / 2$ and $5 / 3$ & $\frac{||{ }_{1} \mid}{2(1+2 \alpha)\left|\alpha_{3}\right|}$ & $\frac{\left|p_{1}\right|}{2|1+2 \alpha|\left|\alpha_{3}\right|}$ \\
$9 / 12$ & $|b|<1$ & $|b| \leq 1$ \\
$11 / 2$ & $\theta(\theta+1) z^{2}$ & $2 \theta^{2} z^{2}$ \\
$11 / 9,11 / 16$ and $11 / 22$ & $\frac{1+\theta}{2}$ & $\theta$ \\
$12 / 4$ & $\alpha_{3} \frac{1+5 \theta}{2}$ & $3 \alpha_{3} \theta$ \\
$12 / 5$ & $\left|1+\theta-4 \mu \frac{\beta_{3} \theta}{\beta_{2}^{2}}\right|$ & $\left|2 \theta-4 \mu \frac{\beta_{3} \theta}{\beta_{2}^{2}}\right|$ \\
\hline
\end{tabular}

Received: 2 October 2013 Accepted: 18 February 2014 Published: 07 Mar 2014

Reference

1. Dziok, J: A general solution of the Fekete-Szegö problem. Bound. Value Probl. 2013, 98 (2013)

10.1186/1687-2770-2014-50

Cite this article as: Dziok: Correction: A general solution of the Fekete-Szegö problem. Boundary Value Problems $2014,2014: 50$
Submit your manuscript to a SpringerOpen ${ }^{\circ}$ journal and benefit from:

- Convenient online submission

Rigorous peer review

- Immediate publication on acceptance

Open access: articles freely available online

- High visibility within the field

Retaining the copyright to your article

Submit your next manuscript at $>$ springeropen.com 